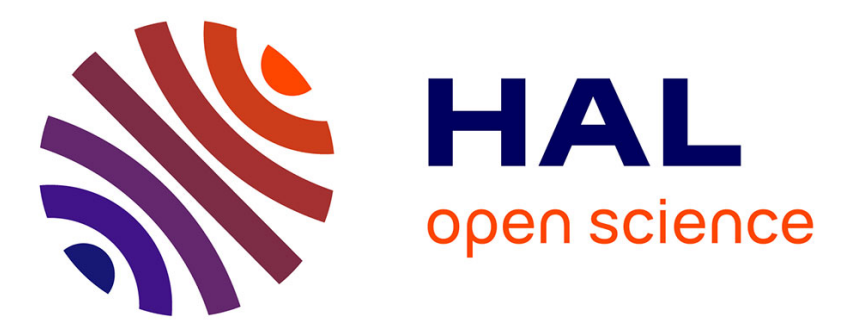

\title{
Substituent Effect on the Himbert Intramolecular Arene/Allene Diels-Alder Reaction: NBO Analysis and State Specific Dual Descriptors
}

Lynda Merzoud, Amar Saal, Christophe Morell, Henry Chermette

\section{- To cite this version:}

Lynda Merzoud, Amar Saal, Christophe Morell, Henry Chermette. Substituent Effect on the Himbert Intramolecular Arene/Allene Diels-Alder Reaction: NBO Analysis and State Specific Dual Descriptors. Journal of Physical Chemistry A, 2019, 123 (50), pp.10730-10738. 10.1021/acs.jpca.9b08773 . hal-02438859

\section{HAL Id: hal-02438859 \\ https://hal.science/hal-02438859}

Submitted on 5 Jun 2020

HAL is a multi-disciplinary open access archive for the deposit and dissemination of scientific research documents, whether they are published or not. The documents may come from teaching and research institutions in France or abroad, or from public or private research centers.
L'archive ouverte pluridisciplinaire HAL, est destinée au dépôt et à la diffusion de documents scientifiques de niveau recherche, publiés ou non, émanant des établissements d'enseignement et de recherche français ou étrangers, des laboratoires publics ou privés. 


\title{
Substituent Effect on the Himbert Intramolecular Arene/Allene Diels-Alder Reaction: NBO analysis and State Specific Dual Descriptors
}

\author{
MERZOUD Lynda, ${ }^{a, b}$ SAAL Amar, ${ }^{a, c}$ MORELL Christophe, ${ }^{b}$ CHERMETTE Henry ${ }^{b, *}$ \\ ${ }^{a}$ Département de Chimie, UMMTO University of Tizi-Ouzou, 15000, Algeria. \\ ${ }^{b}$ Université de Lyon, Université Claude Bernard Lyon 1, Institut des Sciences Analytiques, UMR \\ CNRS 5280, 69622 Villeurbanne Cedex, France \\ ${ }^{c}$ Laboratory of Computational and Theoretical Chemistry and Photonics, USTHB University, 16111, \\ Algeria
}

Corresponding author: henry.chermette@univ-lyon1.fr

\begin{abstract}
Conceptual density functional theory has been applied to study the Himbert intramolecular arene/allene Diels-Alder reaction. The effect of substitutions at different positions on the kinetics of these reactions has been analyzed. Therefore, from the calculation of the activation energies of more than 27 reactions involving concerted mechanisms, the selectivity of these reactions can be predicted and rationalized with the aid of conceptual DFT descriptors.

An application of the two concepts, natural population analysis (NBO) and the state-specific dual descriptor (SSDD) for evaluating substituent effects, allows the investigation of the different interactions that promote a reaction compared to another. The SSDDs computed for the transition state structures provide important information about charge transfer interactions during the chemical reaction. In our case, the SSDD results show that the substituents promoting Himbert reaction have the lowest excitation energies, a fact which facilitates the allene/arene interaction. The NBO results show that according to the nature of the substituent, the Himbert reaction stands as a normal-electron demand or reverse. Thus, the interactions favoring each reaction are mentioned. The geometric deformation observed in the case of $\mathrm{OCH}_{3}$ is at the origin to the emergence of other low interactions between diene and dienophile as well as a strong electronic delocalization stabilizing the arene moiety. The calculated synchronicity indexes show that the Himbert intramolecular Diels-Alder reactions are very synchronous.
\end{abstract}

Keywords: Himbert cycloadduct, Intramolecular Diels-Alder reaction; NBO analysis; Synchronicity; DFT calculations; Conceptual DFT descriptors, State-Specific Dual descriptor. 


\section{Introduction}

The Diels-Alder reaction is one of the most important reactions of organic chemistry both in synthesis and in its mechanistic implications. [1,2] The stereo- and regio-selectivity of this reaction can be used as a powerful tool in the fast synthesis of polycyclic compounds and as a step in the natural products synthesis. The Diels-Alder reaction has been widely investigated at both the theoretical and experimental levels. [3, 4, 5] Unlike the intermolecular Diels-Alder reactions, in the intramolecular Diels-Alder reactions (IMDA), a chain connects the diene and the dienophile moieties. Nowadays, the IMDA reaction is a valuable tool in organic synthesis because it allows the formation of polycyclic compounds in one step. $[6,7,8]$

Himbert and Henn, in 1982, [9] have reported the first intramolecular cyclization of allenic amides bearing an aryl substituent at the N-atom, Scheme 1. Starting from allenecarboxanilide, this reaction provides an efficient and straightforward way to approach complex bridged polycyclic architectures. Kinetics measurements of the substituent effects, performed by the same research group, [10] have been interpreted in terms of a concerted mechanism. [11]. During the past decades, many efforts have been devoted to the study of this reaction. At the early stage, varying the substitution of carboxylic acid derivatives including amide, $[12,10,13]$ ester, $[11,14,15]$ thioester $[16,17,18,19]$ has been widely investigated. By extending the substrate to benzyl allenyl ketones, Vanderwal et al. [16]. have recently obtained other carbonlinked polycyclic architectures. The same group have estimated the activation energies for concerted arene/allene cycloaddition, with $\mathrm{R} 1=$ but-3-enyl and $\mathrm{R} 3=$ methyl, at $32.6 \mathrm{kcal} / \mathrm{mol}$ based on M06-2X/6-311+G(d,p)/CPCM(xylenes) level of theory. Although many achievements have been attained with these different studies, some questions on Himbert IMDA reaction are not yet solved and hence need to be investigated.

Scheme 1. Himbert arene/allene [4+2] Cycloaddition

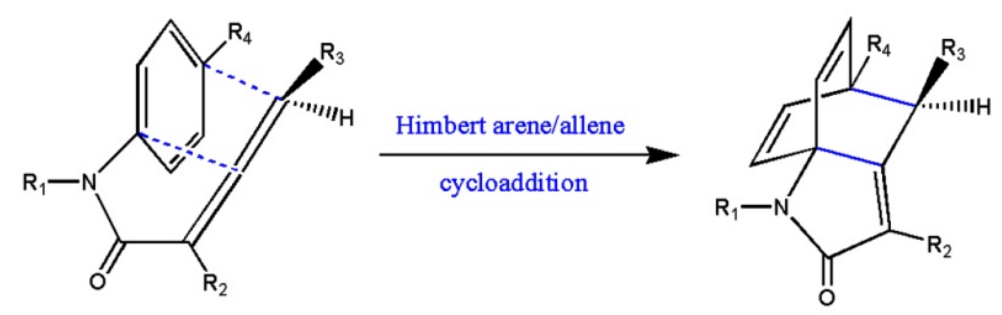

The substitution of chemical systems is the most important fundamental modification in the search of new molecular properties. [20] The substitution effects on the molecular system have 
been semi-quantitatively evaluated by the use of the Hammett substituent constants in the late 1930s. [21] However, the theoretical description of substituent effects has presented a challenge for a long time. In order to investigate the substituents effect on the kinetics of the Himbert IMDA reaction, the natural population analysis (NBO) and State-Specific Dual descriptor (SSDD) have been used. The application of the above mentioned descriptors to a series of R1 and R2 substitued Himbert reactions allows to recognize the action of various substituents and their effect on the activation energy.

The paper is organized as follows: Sec. II is devoted to the description of the theoretical methods utilized in the present work, with an emphasize on the two DFT-derived tools ones used in the present work, Sec. III discusses the Himbert reaction kinetics with respect to the different substituents. The obtained results are explained using the SSDD and the NBO analysis and Sec. IV reports a study of the synchronicity of this IMDA Himbert reaction, which is compared to that of some intermolecular Diels-Alder reactions. The remainder contains some concluding remarks and a summary.

\section{Computational details}

The calculations presented in this work were performed within the framework of density functional theory (DFT). An accurate assessment of various chemical properties, essentially kinetics is allowed with the development of DFT. Recently, Mardirossian et al. [22] and Goerigk et al. [23] have studied in detail the performance of different functionals for various applications of main group chemistry. For this purpose, the comparison of the root-means square derivatives (RMSDs) of the 26 pericyclic reactions barrier heights was carried out with 20 density functionals. By this study, Mardirossian et al. [22] pointed out that the hybrid metaGGA functional, M06-2X, is one of the most efficient ones to investigate this class of reactions. Therefore, the geometries and energies of all stationary points including reactants, transition structures (TS) and products were fully optimized with the M06-2X functional [24, 25], in combination with the aug-cc-pvDZ [27, 28] basis set as implemented in Gaussian09 [26]. Reactants and products were characterized by frequency calculations at the same level. Transition structures show only one negative eigenvalue in their diagonalized force constants matrices. Their associated eigenvectors were confirmed to correspond to the motion along the reaction coordinate under consideration using the Intrinsic Reaction Coordinate (IRC) approach. [29] Natural bond orbital analysis (NBO), [30, 31, 32, 33] (NBO version 3.1 [34] as implemented in Gaussian 09), was used to reveal the $\sigma$ and $\pi$ electron shift between the core 
molecule and the substituent. In all studied reactions, state specific dual descriptors $[35,36]$ calculations at the transition states have been performed at M06-2X/aug-cc-pvDZ level.

\section{Results and Discussion}

Fourteen substituents have been considered in this study to span the effect on both $\pi$ - and $\sigma$ molecular orbitals of the substituted IMDA reactions. The selected substituents cover scales from donating through moderately to strongly electron

withdrawing character. In this investigation, the attention has been focused to study the substituent effects on the Himbert IMDA reaction kinetics using SSDD descriptor and NBO analysis.

\section{III.1. Effect of the nature of the substituent R1 and R2}

In general, the substituent effect on the kinetics of a reaction depends on its nature and its position. In this study, a total of twenty-three reactions have been considered : $\mathrm{R} 1=\mathrm{OCH}_{3}$, $\mathrm{CH}_{3}, \mathrm{Cl}, \mathrm{COOH}, \mathrm{CHO}, \mathrm{H}, \mathrm{SiH}_{3}, \mathrm{Si}(\mathrm{Me})_{3}, \mathrm{SH}, \mathrm{NH}_{2}$ and $\mathrm{R} 2=\mathrm{OCH}_{3}, \mathrm{COOH}, \mathrm{OH}, \mathrm{NH}_{2}$, $\mathrm{N}(\mathrm{Me})_{2}, \mathrm{Cl}, \mathrm{Br}, \mathrm{CHO}, \mathrm{CH}_{3}, \mathrm{H}, \mathrm{BF}_{2}, \mathrm{SiH}_{3}, \mathrm{Si}(\mathrm{Me})_{3}, c f$. Scheme 2

\section{III.1.a. Activation Energy}

First we consider the case with $\mathrm{R} 1=\mathrm{H}$, in order to understand the $\mathrm{R} 1$ substituent effect on the kinetics of Himbert rearrangement. The solvent effect on the reaction kinetics was also evaluated and a minimal stabilization of activation energy $(<1 \mathrm{kcal} / \mathrm{mol})$ was observed. Thus, an activation energy of $28.81 \mathrm{kcal} / \mathrm{mol}$ was obtained using the M06-2X/aug-cc-pvDZ/CPCM (toluene) model for $\mathrm{R}=\mathrm{H}$ case. After the transition state optimization, the obtained IRC paths is plotted in Figure 1

Scheme 2. Arene/allene Himbert Cycloaddition
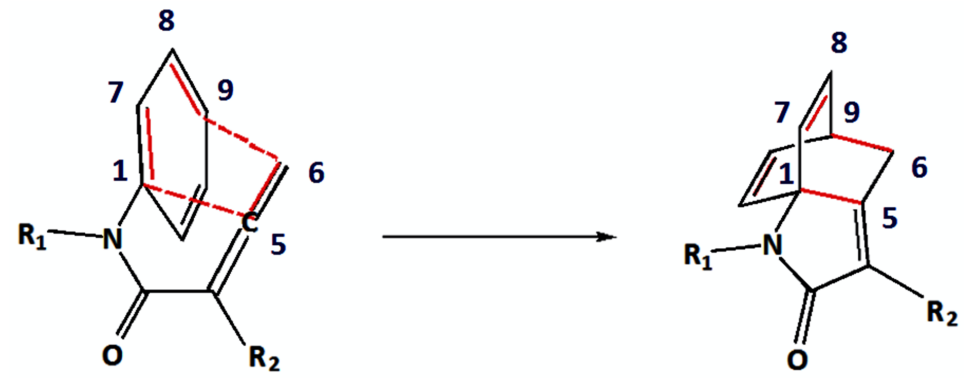
Throughout the IRC path, the difference between the distances participating in the two forming $\sigma$ bonds $\mathrm{dC} 6 \mathrm{C} 9$ and $\mathrm{dC} 5 \mathrm{C} 1$ remains almost constant, which means that the formation of these bonds takes place at the same time, $c f$. Figure 1 (see Scheme 2 for the atom numbers). The Wiberg indices between the atoms involved in the reaction at the reactant, transition state and product are respectively $\beta \mathrm{C} 6 \mathrm{C} 9(0.001,0.411$ and 0.958$)$ and $\beta \mathrm{C} 5 \mathrm{C} 1=(0.003,0.425$ and 0.933$)$. These values indicate that two single bonds are forming. The Wiberg Bond Index values are smaller than $1.0(\approx 0.9$ for product $)$, therefore, the $\mathrm{C}-\mathrm{C}$ bonds are localized. These values indicate that two single bonds are forming.

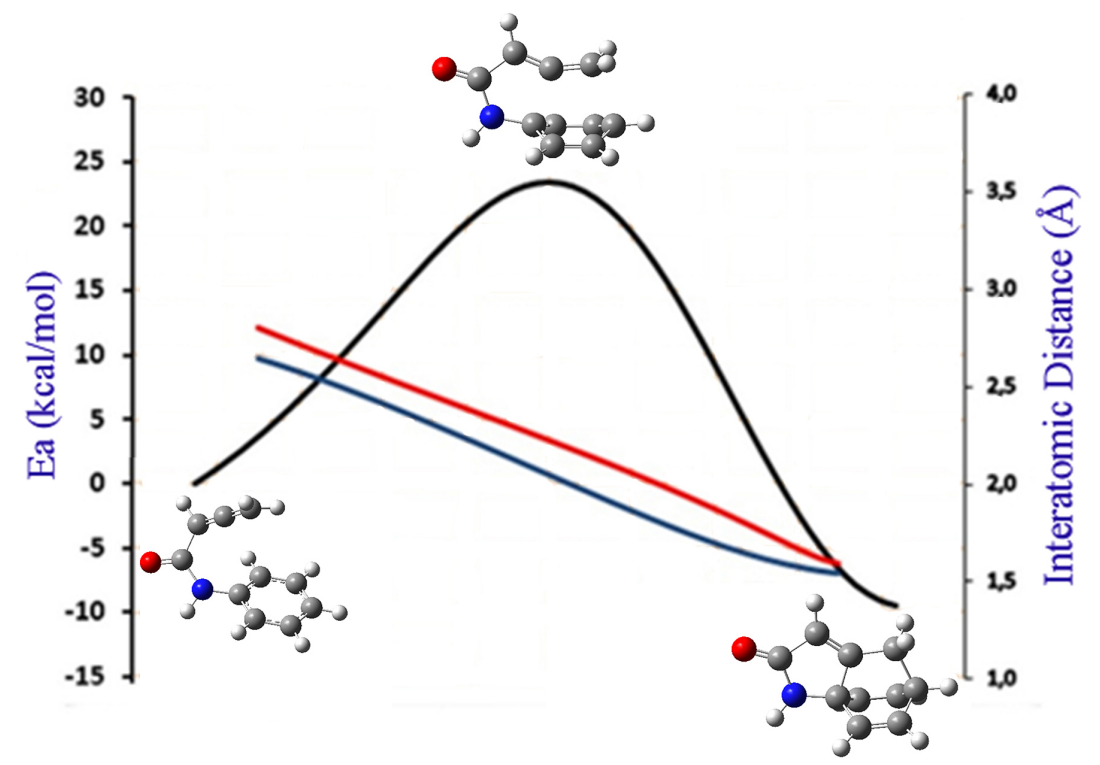

Figure 1. IRC path corresponding to $R I=H$ case. The black curve is energy, the red and blue curves are $d C 6 C 9$ and $d C 5 C 1$ distances, respectively.

In order to extend this study, a set of substituents has been taken into consideration in R1 and R2 (Table 1). The selected substituents cover scales from donating through moderately to strongly electron withdrawing character. As expected, from the results reported in Table 1, the activation energy varies with the nature and the position of the substituent. In both $\mathrm{N}$ and $\mathrm{C} 4$ positions, the highest activation energy is obtained in the case of $\mathrm{R} 1=\mathrm{R} 2=\mathrm{H}$ and the lowest $\mathrm{Ea}$ is obtained in the case of $\mathrm{R} 1=\mathrm{OCH}_{3}$ and $\mathrm{R} 2=\mathrm{OCH}_{3}$ 
Table 1. Activation energy ( $\mathrm{kcal} / \mathrm{mol}$ ) with 13 substituents spanning the substituent effect on Himbert kinetics reaction calculated at M06-2X/aug-cc-pvDZ level.

\begin{tabular}{lllr}
\hline Entry & $\mathrm{R} 1$ & $\mathrm{R} 2$ & Ea \\
\hline 1 & $\mathbf{H}$ & $\mathbf{H}$ & $\mathbf{2 9 . 6 9}$ \\
2 & $\mathbf{C l}$ & $\mathrm{H}$ & 29.17 \\
3 & $\mathbf{S i H}_{3}$ & $\mathrm{H}$ & 28.49 \\
4 & $\mathbf{C H}_{3}$ & $\mathrm{H}$ & 28.24 \\
5 & $\mathbf{S i}(\mathbf{M e})_{3}$ & $\mathrm{H}$ & 27.93 \\
6 & $\mathbf{C H O}$ & $\mathrm{H}$ & 27.83 \\
7 & $\mathbf{C O O H}$ & $\mathrm{H}$ & 26.14 \\
8 & $\mathbf{S H}$ & $\mathrm{H}$ & 25.58 \\
9 & $\mathbf{N H}_{\mathbf{2}}$ & $\mathrm{H}$ & 24.57 \\
10 & $\mathbf{O C H}_{\mathbf{3}}$ & $\mathbf{H}$ & $\mathbf{2 1 . 8 6}$ \\
& & & \\
11 & $\mathbf{C H}_{\mathbf{3}}$ & $\mathbf{H}$ & $\mathbf{2 9 . 2 5}$ \\
12 & $\mathrm{CH}_{3}$ & $\mathbf{S i}(\mathbf{M e})_{\mathbf{3}}$ & 28.24 \\
13 & $\mathrm{CH}_{3}$ & $\mathbf{S i H}$ & 29.16 \\
14 & $\mathrm{CH}_{3}$ & $\mathbf{B F}$ & 28.36 \\
15 & $\mathrm{CH}_{3}$ & $\mathbf{C H}$ & 28.24 \\
16 & $\mathrm{CH}_{3}$ & $\mathbf{C H O}$ & 26.49 \\
17 & $\mathrm{CH}_{3}$ & $\mathbf{N}(\mathbf{M e})_{\mathbf{2}}$ & 25.99 \\
18 & $\mathrm{CH}_{3}$ & $\mathbf{B r}$ & 25.22 \\
19 & $\mathrm{CH}_{3}$ & $\mathbf{C l}$ & 25.03 \\
20 & $\mathrm{CH}_{3}$ & $\mathbf{O H}$ & 25.00 \\
21 & $\mathrm{CH}_{3}$ & $\mathbf{N H}$ & 24.91 \\
22 & $\mathrm{CH}_{3}$ & $\mathbf{C O O H}$ & 24.22 \\
23 & $\mathbf{C H}_{\mathbf{3}}$ & $\mathbf{O C H}$ & $\mathbf{2 2 . 2 3}$ \\
\hline
\end{tabular}

III.1.b. State Specific Dual Descriptor SSDD

The state specific dual descriptor (SSDD) was introduced by Morell et al.[35, 36] in order to understand chemical reactivity further than the DD does. The SSDD is calculated as the difference between excited and the ground states densities and it can be approximated by:

$$
\Delta f(r)=\rho^{i}(r)-\rho^{0}(r)
$$

Where, $\rho^{i}(r)$ is the density of the excited state $i$ and $\rho^{0}(r)$ is the density of the ground state.

In order to evaluate the SSDD, ten excitated states are calculated using the TD-DFT formalism at the TD-M06-2X/aug-cc-pvDZ level of theory. The sign of the dual descriptor characterizes the reactivity of a site within a molecule. Like with the DD, a favorable interaction between 
molecules occurs when the electrophilic regions $(\Delta f(r)>0$ orange regions in the isodensity maps) are aligned with the nucleophilic regions $((\Delta f(r)<0$ green regions in the isodensity maps $)$ and vice versa. $[35,36]$

The excited state energy, where the electron transfer between diene and dienophile has been observed, is plotted in the Figure 2. It is important to note that this excitation energy currently constitutes a relevant parameter indicating the amount of energy needed to trigger the electron transfer between two interacting moieties. For both R1 and R2 cases, it is plain from a visual inspection of the different SSDD descriptors that there is an electron transfer between the allene and the arene moieties. So, in all studied reactions, the direction of electron flow is from the allene to the arene moiety. As can be seen in Figure 2, the SSDD results show that the activation energy decreases with the decrease of the excited state energy where the electronic donation takes place.

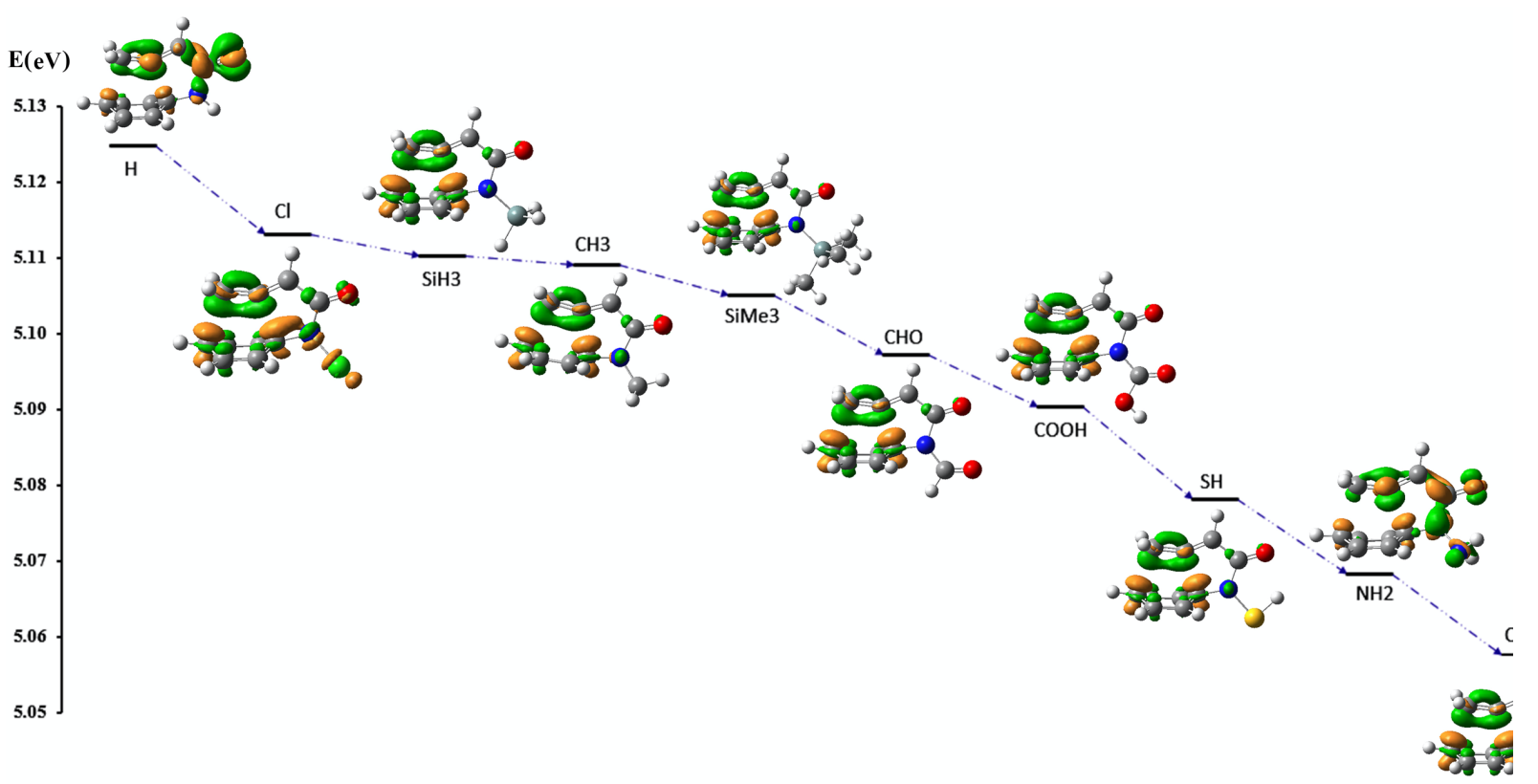

(A) 


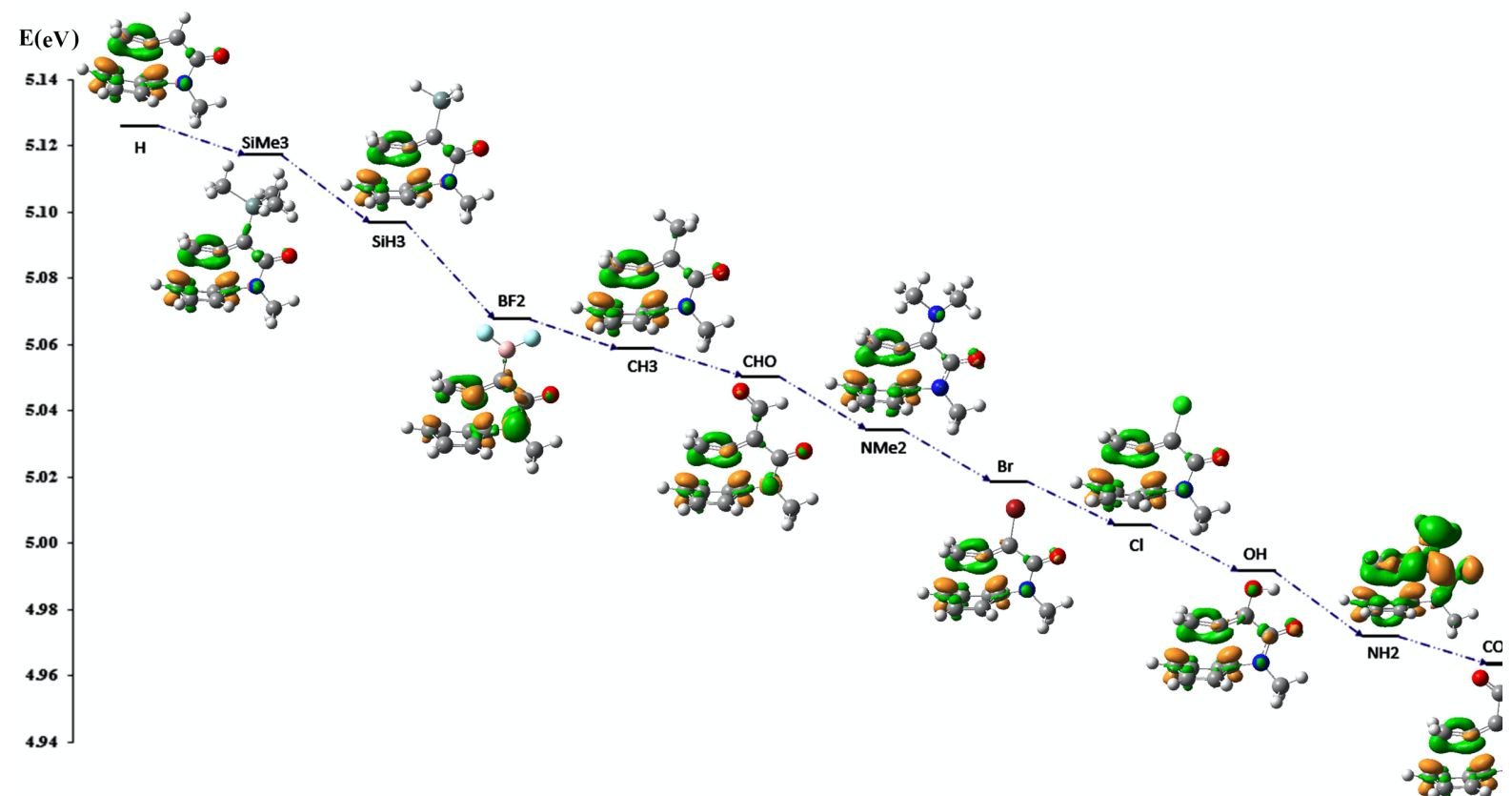

(B)

Figure 2. State-specific dual descriptor of the interactions between Allene/Arene for the studied Himbert Intramolecular Diels-Alder Reactions (Green lobes correspond to negative values of the dual descriptor, whereas orange lobes correspond to positive ones). The vertical scale concerns the transition state donation energy in $\mathrm{eV}$ (fig. (A) corresponds to varying substituent $R 1$ with $R 2=H$, and Fig. (B) corresponds to varying substituent $R 2$ with $R 1=C_{3}$ ).

In order to explore a possible correlation between the SSDD value and the kinetics of the studied Himbert IMDA reaction, the donation energy of these reactions has been plotted as a function of the activation energy for all substituent, $c f$. Figure 3. The plot in Figure 3 exhibits almost a linear correlation. Thus, for both cases R1 and R2, the decrease in activation energy varies proportionally with the interaction energy between diene and dienophile, i.e. with the donation energy. 


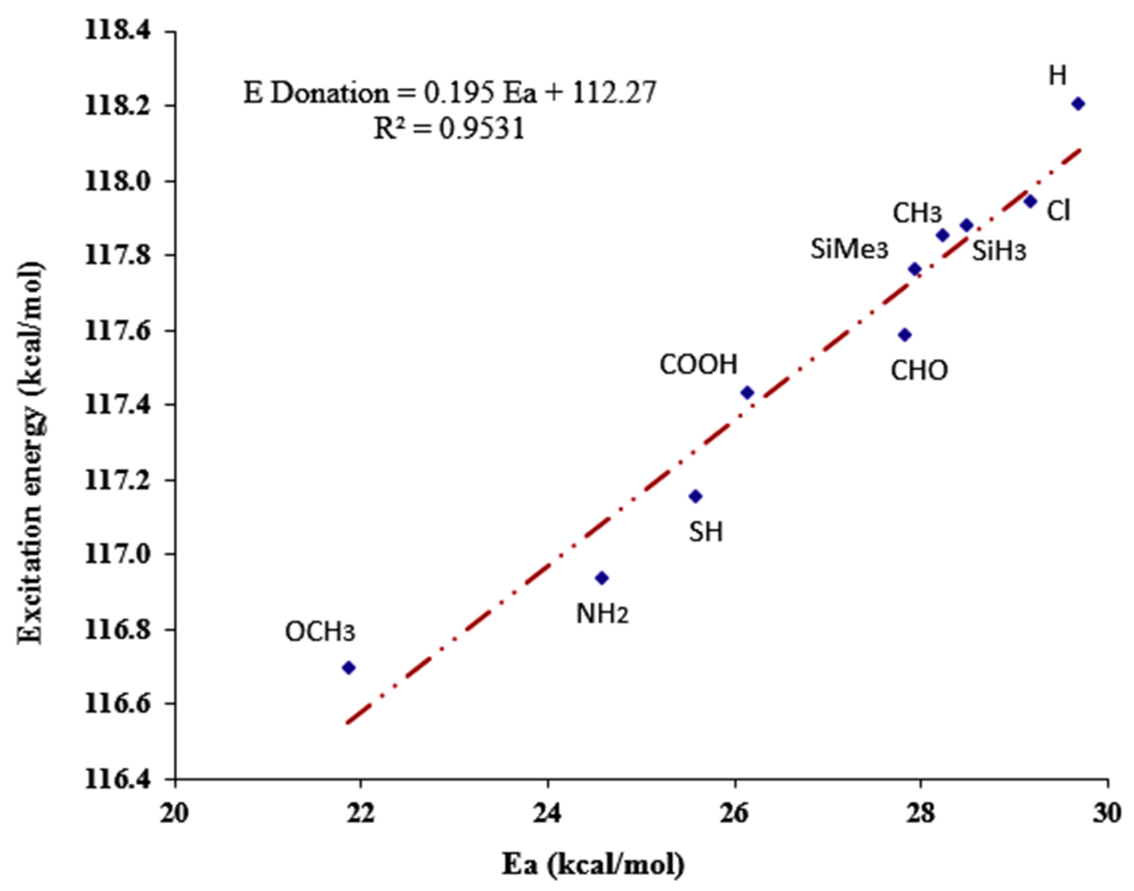

(A)

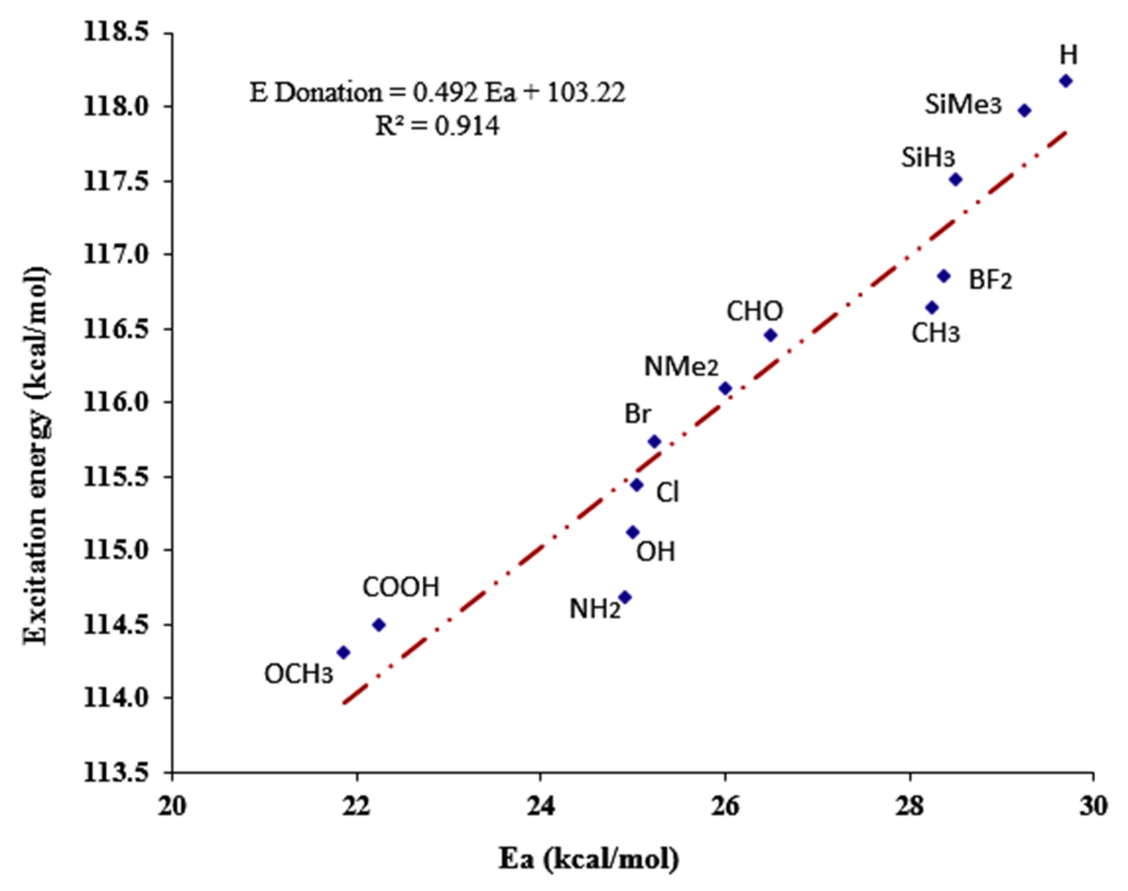

(B)

Figure 3. Variation of the IMDA reaction donation energy $(\mathrm{kcal} / \mathrm{mol})$ in function of the activation energy of the R1(fig. 3.A) and R2 (Fig. 3.B) substituents 


\section{III.1.c. NBO analysis}

In order to explore deeply the interactions between the molecular orbitals at the transition states of the studied reactions, hyperconjugative interactions have been evaluated in each case. To do so, we have made a natural bond orbital (NBO) analysis [30, 31, 32, 33].

In a NBO analysis, each localized bond between two atoms A and B is represented by two natural bond orbitals (NBOs): the Lewis bond type (a bonding) $\mathrm{NBO}_{\mathrm{AB}}$ and the non-Lewis bond type (a non- bonding) $\mathrm{NBO}^{*}{ }_{\mathrm{AB}}$

$$
\begin{aligned}
& N B O_{A B}=c_{A} N H O_{A}+c_{B} N H O_{B} \\
& N B O_{A B}^{*}=c_{A} N H O_{A}-c_{B} N H O_{B}
\end{aligned}
$$

Where $c_{A}$ and $c_{B}$ are the coefficients, and $N H O_{A}$ and $N H O_{B}$ are the natural hybrid orbitals of $A$ and $B$. In the idealized Lewis structure, the bonding NBOs are filled and the anti-bonding NBOs, i.e. the NBOs*, are totally empty. With NBO analysis, the energy associated with the antibonds can be numerically assessed. In this way one obtains a decomposition of the total energy $E$ in to the covalent components (E Lewis) and noncovalent (E non-Lewis) contributions such as $\mathrm{E}=\mathrm{E}$ Lewis $+\mathrm{E}$ non-Lewis. The difference between ( $\mathrm{E}-\mathrm{E}$ Lewis) give the deviation to the formal Lewis representation. In reality, several interactions (charge transfer, conjugation, hyperconjugation ...) that are not taken into account in formal Lewis representation generate this deviation between the real structures and the Lewis representation. These non-covalent effects can be described by considering the interactions between occupied and non-occupied NBOs. These corrections are usually designated as: charge transfer, donor-acceptor, or Lewisbase-Lewis-acid interactions. Energetic stabilization of the real structure relatively to the formal Lewis structure is evaluated by considering the bond-anti-bond charge transfer. Hence, for a given pair of $\mathrm{NBOs,} \mathrm{occupied} \mathrm{NBO}(i)$ and partially occupied $\mathrm{NBO}(j)$, the stabilization energy due to the charge delocalization $N B O(i) \rightarrow N B O(j)$ is:

$$
E^{(2)}=q_{i} \frac{F_{i j}^{2}}{\varepsilon_{j}-\varepsilon_{i}}
$$


$E^{(2)}$ is the second-order correction energy [37], $F_{i j}$ is the Fock matrix elements between the NBO orbitals $i$ and $j, \varepsilon_{j}-\varepsilon_{i}$ is the energy difference between the donor $N B O(i)$ and the acceptor $N B O(j)$, and $q_{i}$ is the charge of $N B O(i)$.

The second order perturbation theory analysis of the Fock matrix for the different transition states has been performed. Subsequently, a comparison between the different reactions was made in order to find the interactions responsible for the decrease of the activation energy as a function of the substituents variation. Thus, this comparison was made between two successive reactions and follows the order: $\mathrm{H} ; \mathrm{Cl} ; \mathrm{SiH}_{3} ; \mathrm{CH}_{3} ; \mathrm{Si}(\mathrm{Me})_{3} ; \mathrm{CHO} ; \mathrm{COOH} ; \mathrm{SH} ; \mathrm{NH}_{2} ; \mathrm{OCH}_{3}$; in R1 case.

First we analyze the $\mathrm{R} 1=\mathrm{H}$ case. This reaction is slower than those with all other substituents in $\mathrm{R} 1$. The NBO results show that in the case of $\mathrm{R} 1=\mathrm{H}$, the Himbert rearrangement is classified as a normal-electron demand reaction. Therefore, the Himbert reaction features electron-poor dienes i.e. arene interacting with an electron-rich dienophiles i.e. allene. In this case, the diene is enriched by part from the nitrogen lone pair that interacts with the arene as follows: $n(1) \mathrm{N}_{2}$ $\rightarrow \pi * \mathrm{C}_{1} \mathrm{C}_{11}\left(\mathrm{E}^{(2)}=20.5 \mathrm{kcal} / \mathrm{mol}\right)$

Simultaneously, the dienophile is depleted in electrons which are attracted by the $\mathrm{C}_{3} \mathrm{O}_{12}$ bond. The SSDD results $c f$. Figure 2 show a large electron density localization on this bond which is confirmed by the NBO results.

$$
\begin{array}{ll}
\mathrm{n}(1) \mathrm{N}_{2} \rightarrow \pi * \mathrm{C}_{3} & \mathrm{E}^{(2)}=60.0 \mathrm{kcal} / \mathrm{mol} \\
\mathrm{C}_{12} & \mathrm{E}^{(2)}=17.2 \mathrm{kcal} / \mathrm{mol} \\
\pi \mathrm{C}_{4} \mathrm{C}_{5} \rightarrow \pi^{*} \mathrm{C}_{3} \mathrm{C}_{12} & \mathrm{E}^{(2)}=8.6 \mathrm{kcal} / \mathrm{mol} \\
\sigma \mathrm{C}_{5} \mathrm{C}_{6} \rightarrow \sigma^{*} \mathrm{C}_{4} \mathrm{C}_{5} & \mathrm{E}^{(2)}=7.1 \mathrm{kcal} / \mathrm{mol} \\
\pi \mathrm{C}_{5} \mathrm{C}_{6} \rightarrow \sigma^{*} \mathrm{C}_{4} \mathrm{C}_{5} &
\end{array}
$$

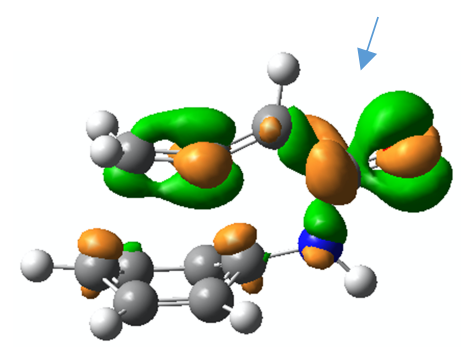

The simple substitution of a hydrogen atom by a chlorine atom in R1 slightly reduces the activation energy. This simple substitution modifies the electronic demand of the reaction. Thus, in the $\mathrm{R} 1=\mathrm{Cl}$ case, the Himbert rearrangement is inverse-electron demand reaction. In the 
following, the donor-acceptor hyperconjugative interactions leading to the stabilization provided by the chlorine atom are given. Therefore, this inverse Diels-Alder reaction features electron-poor dienes and electron-rich dienophiles

Diene:

$$
\begin{array}{ll}
\pi \mathrm{C}_{1} \mathrm{C}_{7} \rightarrow \sigma^{*} \mathrm{~N}_{2} \mathrm{Cl}_{21} & \mathrm{E}^{(2)}=23.2 \mathrm{kcal} / \mathrm{mol} \\
\sigma \mathrm{C}_{10} \mathrm{C}_{11} \rightarrow \sigma^{*} \mathrm{C}_{1} \mathrm{~N}_{2} & \mathrm{E}^{(2)}=5.4 \mathrm{kcal} / \mathrm{mol}
\end{array}
$$

Dienophile:

$$
\begin{array}{cl}
\mathrm{n}(1) \mathrm{N}_{2} \rightarrow \pi^{*} \mathrm{C}_{3} \mathrm{C}_{12} & \mathrm{E}^{(2)}=44.6 \mathrm{kcal} / \mathrm{mol} \\
\pi^{*} \mathrm{C}_{3} \mathrm{C}_{12} \rightarrow \pi^{*} \mathrm{C}_{4} \mathrm{C}_{5} & \mathrm{E}^{(2)}=39.1 \mathrm{kcal} / \mathrm{mol} \\
\mathrm{n}(2) \mathrm{O}_{12} \rightarrow \sigma^{*} \mathrm{~N}_{2} \mathrm{C}_{3} & \mathrm{E}^{(2)}=35.3 \mathrm{kcal} / \mathrm{mol} \\
\mathrm{n}(2) \mathrm{O}_{12} \rightarrow \sigma^{*} \mathrm{C}_{3} \mathrm{C}_{4} & \mathrm{E}^{(2)}=22.4 \mathrm{kcal} / \mathrm{mol} \\
\mathrm{n}(2) \mathrm{O}_{12} \rightarrow \mathrm{Ry}^{*} \mathrm{C}_{3} & \mathrm{E}^{(2)}=14.6 \mathrm{kcal} / \mathrm{mol} \\
\sigma \mathrm{C}_{3} \mathrm{C}_{4} \rightarrow \sigma^{*} \mathrm{C}_{5} \mathrm{C}_{6} & \mathrm{E}^{(2)}=5.2 \mathrm{kcal} / \mathrm{mol} \\
\sigma \mathrm{C}_{4} \mathrm{C}_{5} \rightarrow \sigma^{*} \mathrm{C}_{5} \mathrm{C}_{6} & \mathrm{E}^{(2)}=8.4 \mathrm{kcal} / \mathrm{mol}
\end{array}
$$
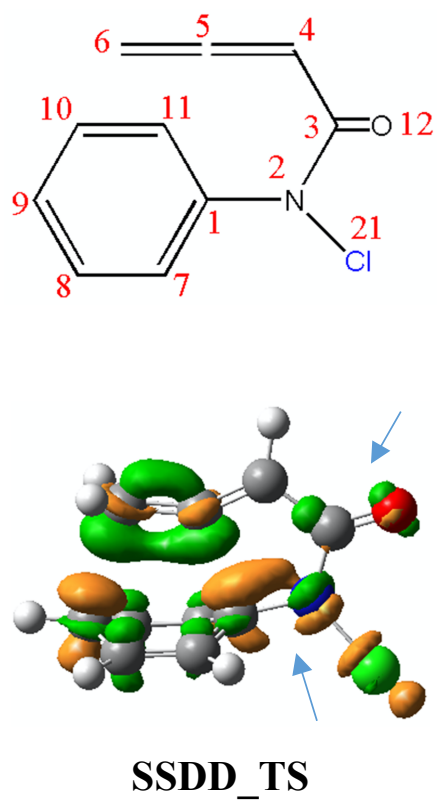

Contrary to the hydrogen case, the chlorine atom acts as an electron-withdrawing group (EWG) that decreases the HOMO-LUMO energy gap from $7.431 \mathrm{eV}$ for $\mathrm{R} 1=\mathrm{H}$ to $7.430 \mathrm{eV}$ for $\mathrm{R} 1=$ $\mathrm{Cl}$ and the dienophile is enriched by oxygen $\mathrm{O}_{12}$.

The NBO results show that the presence of other weak interactions in $\mathrm{R} 1=\mathrm{Cl}$ case should be at the origin of this slight decrease in activation energy.

$$
\begin{array}{ll}
\sigma \mathrm{C}_{1} \mathrm{~N}_{2} \rightarrow \sigma * \mathrm{C}_{3} \mathrm{O}_{12} & \mathrm{E}^{(2)}=2.1 \mathrm{kcal} / \mathrm{mol} \\
\sigma \mathrm{C}_{3} \mathrm{C}_{4} \rightarrow \sigma * \mathrm{C}_{3} \mathrm{O}_{12} & \mathrm{E}^{(2)}=0.6 \mathrm{kcal} / \mathrm{mol}
\end{array}
$$

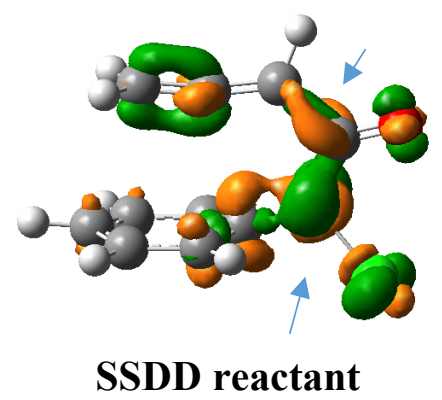

$$
\begin{array}{ll}
\mathrm{n} \mathrm{Cl}_{21} \rightarrow \sigma^{*} \mathrm{C}_{1} \mathrm{~N}_{2} & \mathrm{E}^{(2)}=1.6 \mathrm{kcal} / \mathrm{mol} \\
\mathrm{n} \mathrm{Cl}_{21} \rightarrow \mathrm{Ry}^{*} \mathrm{~N}_{2} & \mathrm{E}^{(2)}=0.8 \mathrm{kcal} / \mathrm{mol} \\
& \mathrm{E}^{(2)}=1.8 \mathrm{kcal} / \mathrm{mol}
\end{array}
$$




$$
\begin{array}{ll}
\mathrm{n} \mathrm{Cl}_{21} & \rightarrow \sigma^{*} \mathrm{~N}_{2} \mathrm{C}_{3} \\
\mathrm{n} \mathrm{Cl}_{21} & \rightarrow \sigma^{*} \mathrm{C}_{3} \mathrm{C}_{4}
\end{array}
$$

As for the hydrogen case, the Himbert reaction substituted with $\mathrm{SiH}_{3}$ is a normal-electron demand reaction. The NBO results showing donor-acceptor interactions stabilizing Himbert reaction substituted with $\mathrm{SiH}_{3}$ versus chlorine substituted reaction are shown in the following Table:

Diene rich:

$$
\begin{array}{cl}
\pi \mathrm{C}_{9} \mathrm{C}_{10} \rightarrow \pi^{*} \mathrm{C}_{7} \mathrm{C}_{8} & \mathrm{E}^{(2)}=29.4 \mathrm{kcal} / \mathrm{mol} \\
\mathrm{n}(2) \mathrm{N}_{2} \rightarrow \sigma^{*} \mathrm{C}_{1} \mathrm{C}_{7} & \mathrm{E}^{(2)}=0.6 \mathrm{kcal} / \mathrm{mol} \\
\mathrm{n}(2) \mathrm{N}_{2} \rightarrow \pi^{*} \mathrm{C}_{1} \mathrm{C}_{7} & \mathrm{E}^{(2)}=10.7 \mathrm{kcal} / \mathrm{mol}
\end{array}
$$

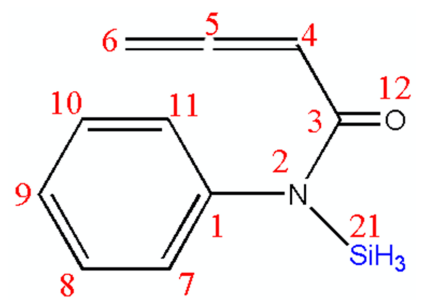

Dienophile:

$$
\pi \mathrm{C}_{4} \mathrm{C}_{5} \rightarrow \pi^{*} \mathrm{C}_{3} \mathrm{O}_{12} \quad \mathrm{E}^{(2)}=19.7 \mathrm{kcal} / \mathrm{mol}
$$

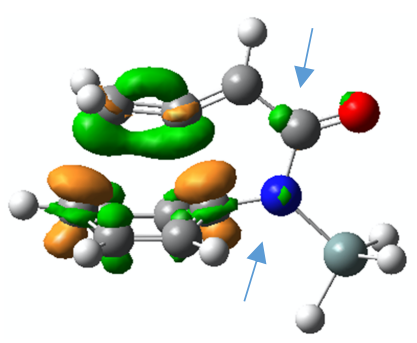

$$
\text { SSDD_TS }
$$

In this reaction, the nitrogen lone pair stabilizes the bonds constituting the chain connecting the diene to the dienophile in this intramolecular reaction. This electron density will be attracted by the silicon atom.

$$
\begin{array}{ll}
\mathrm{n}(2) \mathrm{N}_{2} \rightarrow \mathrm{Ry}^{*} \mathrm{C}_{1} & \mathrm{E}^{(2)}=2.7 \mathrm{kcal} / \mathrm{mol} \\
\mathrm{n}(2) \mathrm{N}_{2} \rightarrow \mathrm{Ry}^{*} \mathrm{C}_{3} & \mathrm{E}^{(2)}=1.6 \mathrm{kcal} / \mathrm{mol} \\
\mathrm{n}(2) \mathrm{N}_{2} \rightarrow \sigma^{*} \mathrm{C}_{1} \mathrm{~N}_{2} & \mathrm{E}^{(2)}=1.3 \mathrm{kcal} / \mathrm{mol} \\
\mathrm{n}(2) \mathrm{N}_{2} \rightarrow \sigma^{*} \mathrm{C}_{3} \mathrm{C}_{4} & \mathrm{E}^{(2)}=7.4 \mathrm{kcal} / \mathrm{mol} \\
\sigma^{*} \mathrm{C}_{1} \mathrm{~N}_{2} \rightarrow \mathrm{n}^{*} \mathrm{Si}_{21} & \mathrm{E}^{(2)}=17.7 \mathrm{kcal} / \mathrm{mol}
\end{array}
$$

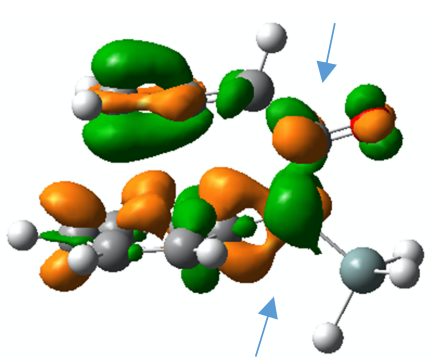

SSDD_Reactant 


$$
\begin{array}{ll}
\sigma^{*} \mathrm{~N}_{2} \mathrm{C}_{3} \rightarrow \mathrm{n}^{*} \mathrm{Si}_{21} & \mathrm{E}^{(2)}=19.0 \mathrm{kcal} / \mathrm{mol} \\
\sigma^{*} \mathrm{C}_{3} \mathrm{C}_{4} \rightarrow \mathrm{n}^{*} \mathrm{Si}_{21} & \mathrm{E}^{(2)}=2.2 \mathrm{kcal} / \mathrm{mol} \\
\mathrm{n}(1) \mathrm{N}_{2} \rightarrow \mathrm{n}^{*} \mathrm{Si}_{21} & \mathrm{E}^{(2)}=4.3 \mathrm{kcal} / \mathrm{mol} \\
\mathrm{n}(2) \mathrm{N}_{2} \rightarrow \mathrm{n}^{*} \mathrm{Si}_{21} & \mathrm{E}^{(2)}=249.2 \mathrm{kcal} / \mathrm{mol}
\end{array}
$$

The NBO results of the other reactions are given in the Supporting Information. According to the substituent used, the Himbert reaction is either in normal-electron demand or reverseelectron demand as mentioned in supporting information. All substituents used in R1 act as an electron-withdrawing groups (EWG).

For $\mathrm{R} 1=\mathrm{NH}_{2}$ case, the observed SSDD at the first stage of the reaction (i.e. at the reactant) is the same as the others substituents. This IMDA reaction is in an inverse electron demand mode as shown the NBO results. However, at the transition structure, the high stabilization of the chain connecting the diene to the dienophile with $\mathrm{NH}_{2}$ and the $\mathrm{N}_{21}$ lone pair, allows the $\mathrm{N}_{2}$ and $\mathrm{O}_{12}$ lone pairs as well as the $\mathrm{C}_{3} \mathrm{O}_{12}$ double bond to enrich the dienophile (more details in Supporting Information)

Finally, we will examine the NBO results of the substituent leading to the lowest activation energy, namely $\mathrm{OCH}_{3}$. The $\mathrm{NBO}$ results show that in the $\mathrm{OCH}_{3}$ case, the Himbert rearrangement is a reverse-electron demand reaction. However, these results show the emergence of other low interactions between diene and dienophile as well as a strong electronic delocalization stabilizing the arene moiety

Diene

$$
\begin{aligned}
& \pi \mathrm{C}_{1} \mathrm{C}_{7} \rightarrow \sigma^{*} \mathrm{~N}_{2} \mathrm{O}_{21} \quad \mathrm{E}^{(2)}=5.9 \mathrm{kcal} / \mathrm{mol} \\
& \mathrm{n}(1) \mathrm{O}_{21} \rightarrow \pi^{*} \mathrm{C}_{1} \mathrm{C}_{7} \quad \mathrm{E}^{(2)}=1.0 \mathrm{kcal} / \mathrm{mol} \\
& \pi^{*} \mathrm{C}_{1} \mathrm{C}_{7} \rightarrow \pi^{*} \mathrm{C}_{5} \mathrm{C}_{6} \quad \mathrm{E}^{(2)}=1.8 \mathrm{kcal} / \mathrm{mol} \\
& \begin{array}{ll}
\pi^{*} \mathrm{C}_{1} \mathrm{C}_{11} \rightarrow \pi * \mathrm{C}_{10} & \mathrm{E}^{(2)}=353.7 \mathrm{kcal} / \mathrm{mol} \\
& \mathbf{E}^{(2)}=305.2 \mathrm{kcal} / \mathrm{mol}
\end{array} \\
& \mathrm{C}_{11} \\
& \pi * \mathrm{C}_{8} \mathrm{C}_{9} \rightarrow \pi * \mathrm{C}_{7} \mathrm{C}_{8}
\end{aligned}
$$

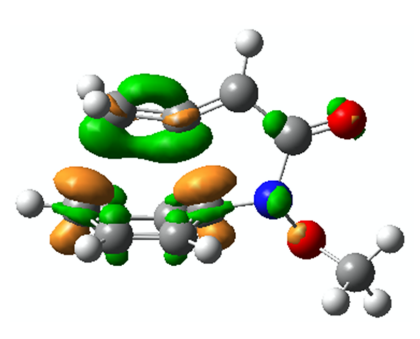

SSDD_TS

Dienophile: 


$$
\begin{array}{ll}
\sigma \mathrm{C}_{4} \mathrm{H}_{13} \rightarrow \pi^{*} \mathrm{C}_{5} \mathrm{C}_{6} & \mathrm{E}^{(2)}=12.7 \mathrm{kcal} / \mathrm{mol} \\
\sigma \mathrm{C}_{6} \mathrm{H}_{15} \rightarrow \pi^{*} \mathrm{C}_{4} \mathrm{C}_{5} & \mathrm{E}^{(2)}=6.9 \mathrm{kcal} / \mathrm{mol} \\
\mathrm{n}(1) \mathrm{N}_{2} \rightarrow \sigma^{*} \mathrm{C}_{3} \mathrm{C}_{4} & \mathrm{E}^{(2)}=0.7 \mathrm{kcal} / \mathrm{mol} \\
\mathrm{n}(2) \mathrm{O}_{12} \rightarrow \sigma^{*} \mathrm{~N}_{2} \mathrm{C}_{3} & \mathrm{E}^{(2)}=34.9 \mathrm{kcal} / \mathrm{mol} \\
\sigma \mathrm{N}_{2} \mathrm{O}_{21} \rightarrow \sigma^{*} \mathrm{C}_{3} \mathrm{O}_{12} & \\
\sigma \mathrm{C}_{22} \mathrm{H}_{23} \rightarrow \sigma^{*} \mathrm{~N}_{2} & \mathrm{E}^{(2)}=0.7 \mathrm{kcal} / \mathrm{mol} \\
\mathrm{O}_{21} & \mathrm{E}^{(2)}=4.6 \mathrm{kcal} / \mathrm{mol} \\
\mathrm{n}(2) \mathrm{O}_{21} \rightarrow \sigma^{*} \mathrm{C}_{1} \mathrm{~N}_{2} & \mathrm{E}^{(2)}=2.1 \mathrm{kcal} / \mathrm{mol} \\
\mathrm{n}(2) \mathrm{O}_{21} \rightarrow \sigma^{*} \mathrm{~N}_{2} \mathrm{C}_{3} &
\end{array}
$$
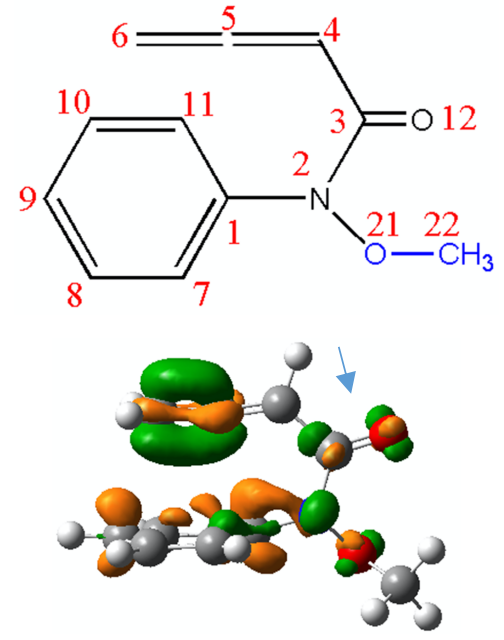

SSDD reactant

\section{IV.1. Effect of the nature of the substituents $R 3$ and $R 4$}

In general, the reactivity of a Diels-Alder reaction depends on the reacting molecular orbitals (RMOs) energies. Electron-withdrawing substituents on the reacting atoms decrease the energy levels of the molecular orbitals particularly those of these RMOs, while electron-donating groups increase their energies. In normal electron-demand Diels-Alder reactions, electrondonating substituents at the diene and/or electron-withdrawing substituents at the dienophile promote this. Thus, the IMDA reaction can be tuned by introducing either electron-withdrawing or electron-donating substituents at proper positions of the diene and the dienophile, Scheme 3.

Scheme 3. Himbert arene/allene [4+2] cycloaddition substitution in R3and R4.

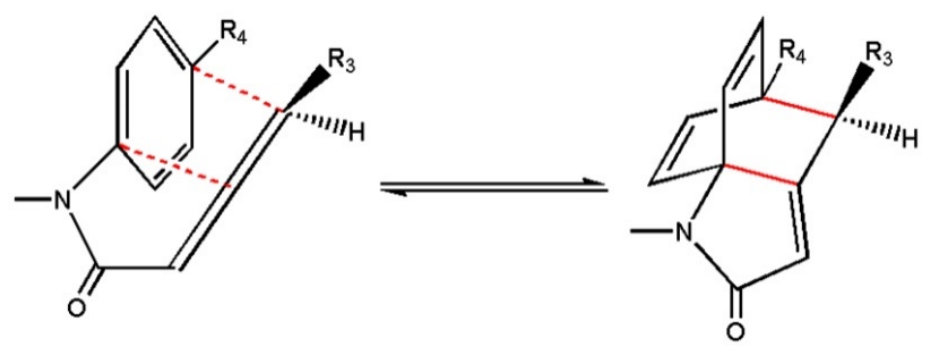


In this study, the introduction of electron withdrawing group at R3 promotes the reaction and may further accelerate the Diels-Alder reaction by increasing the energy of the diene reacting orbitals, Figure 4A. This system undergoes normal electron demand Diels-Alder reaction. On the other hand, the IMDA reaction is favored by an electron-donating at R4. This reaction undergoes a regio-specific normal demand.

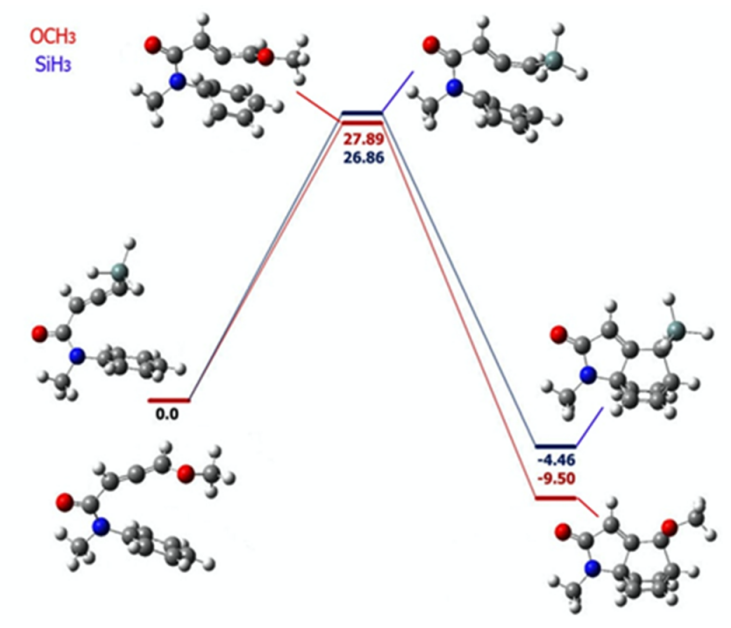

$\boldsymbol{A}$

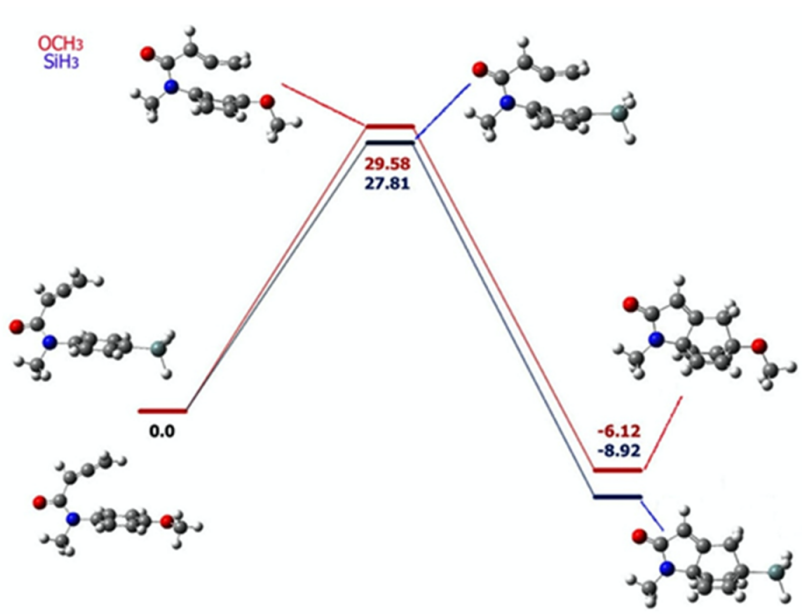

$\boldsymbol{B}$

Figure 4. Calculated energies (kcal/mol) for the Himbert arene/allene cycloaddition. All the calculations were made at M06-2X/aug-cc-pvDZ level; Fig. $\mathrm{A}: \mathrm{R3}=\mathrm{OCH}_{3}$ (in red) and $\mathrm{R} 3=\mathrm{SiH}_{3}$ (in blue); Fig. $\mathrm{B}: \mathrm{R} 4=\mathrm{OCH}_{3}$ (in red) and $\mathrm{R} 4=\mathrm{SiH}_{3}$ (in blue).

\section{IV.2.Synchronicity of the intra- and intermolecular Diels-Alder reactions}

For a given concerted reaction, the synchronicity index can be quantified by the relation: [38, 39]

$$
S y=1-\frac{\sum_{i=1}^{n} \frac{\left|\delta \beta_{i}-\delta \beta_{a v}\right|}{\delta \beta_{a v}}}{2 n-2}
$$

Where $n$ is the number of the involved bonds in the reaction. $\delta \beta_{i}$ represents the relative variation of a given Wiberg bond index [40] at the TS with respect to those of the reactants and the products following the expression: 


$$
\delta \beta_{i}=\frac{\left(\beta_{i}^{T S}-\beta_{i}^{R}\right)}{\left(\beta_{i}^{P}-\beta_{i}^{R}\right)}
$$

$\delta \beta_{\text {av }}$ is simply the average of $\delta \beta_{\mathrm{i}}$ values. The Wiberg bond indices $\delta \beta_{\mathrm{i}}[40]$ were computed using the natural bond orbital (NBO) analysis. [30, 31, 32, 33].

The synchronicity of the studied Himbert IMDA reaction is compared to other Diels-Alder reactions in Table 2. Relatively to the intermolecular Diels-Alder, the considered IMDA reactions are more synchronous. In order to investigate the effect of the allene moiety on the synchronicity of the Himbert IMDA reaction, we have studied the intramolecular arene/ethylene cycloaddition. The obtained results, Table 1 and Figure 5, $(\mathrm{Sy}=0.96)$ confirm the fact that the allene moiety makes the Himbert reaction slightly less synchronous than ethylene.

Table 2. Synchronicities calculated at M06-2X/aug-cc-pvDZ level for various Diels-Alder reaction.

\begin{tabular}{cll}
\hline Entry & Reactants & Sy \\
\hline 1 & Cyclopentadiene/ethylene & 0.93 \\
2 & 7-(methoxymethyl)cyclopentadiene/chloroacrylonitrile (syn) & 0.82 \\
3 & 7-(methoxymethyl)cyclopentadiene/chloroacrylonitrile (anti) & 0.86 \\
4 & Cyclopentadiene/cis-dimethylmaleate (exo) & 0.87 \\
5 & Cyclopentadiene/cis-dimethylmaleate (endo) & 0.54 \\
6 & Cyclopentadiene/trans-dimethylmaleate & 0.91 \\
7 & Himbert arene/allene cycloaddition & 0.94 \\
8 & Himbert arene/ethylene cycloaddition & 0.96 \\
\hline
\end{tabular}




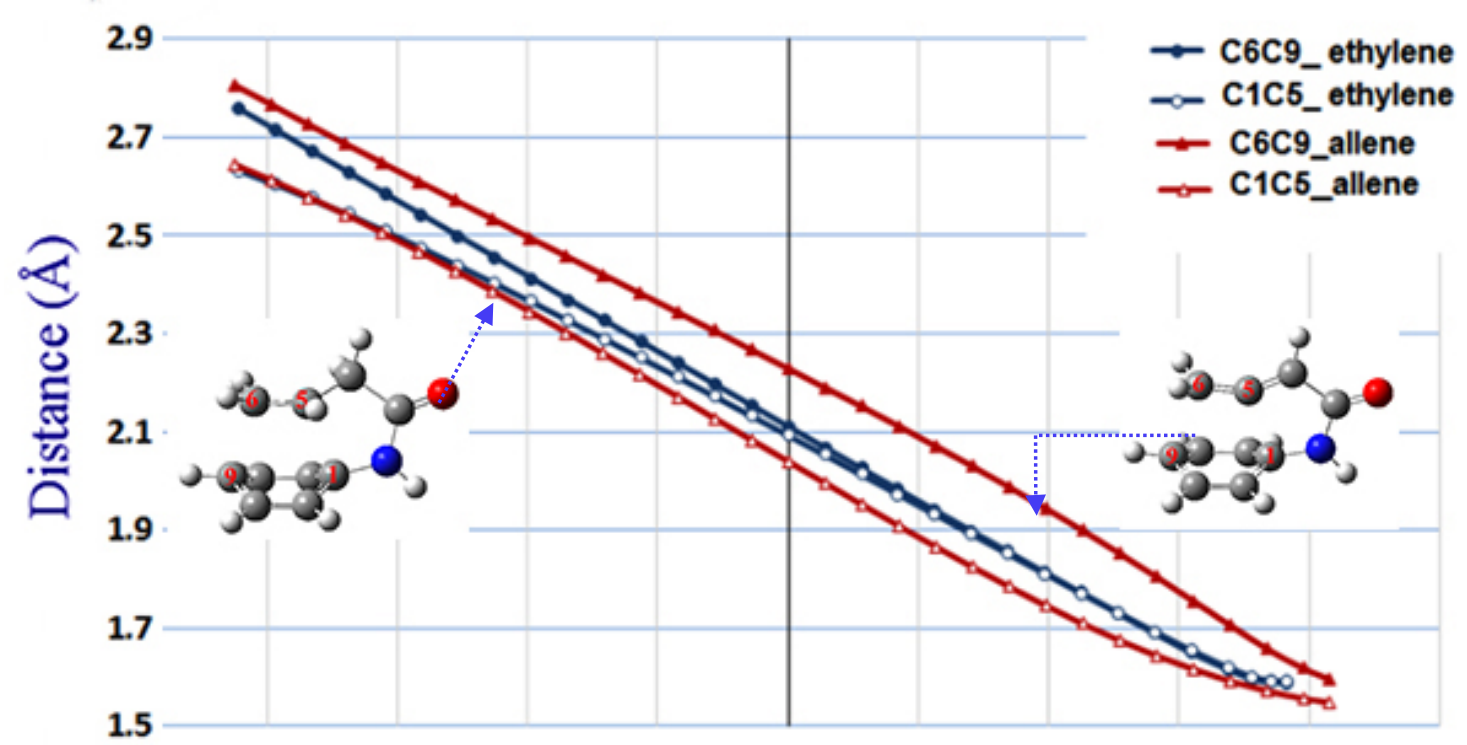

Figure 5. Variation of the intermolecular distances corresponding to the Himbert arene/allene (red) and arene/ethylene (blue) cycloaddition reaction obtained at M06-2X/aug-cc-pvDZ level

\section{Conclusion:}

The substituent effect on the kinetics of IMDA reaction has been investigated. A set of 14 substituents and a total of 27 reactions has been considered.

The variation of the activation energy as function of the substituent has been studied. The results show that the nature and the position of the substituent affect substantially the activation energy of the Himbert IMDA reaction. Here, the state-specific dual descriptor (SSDD) calculations have shown that the substituents lowering the excitation energy, thus facilitating the allene/arene moieties interaction, promote the Himbert reaction. The NBO results has exhibited allows predicting the donor-acceptor interactions promoting the Himbert IMDA reaction. Finally, relatively to intermolecular Diels-Alder reactions, the considered Himbert IMDA reactions are more synchronous. 


\section{Conflicts of interest}

There are no conflicts to declare.

\section{Acknowledgements}

The authors gratefully acknowledge the GENCI/CINES for HPC resources/computer time (Project cpt2130).

\section{Supporting Information Available:}

1. NBO analyses

2. SSDD calculation for R2 substituent

3. Geometry structures

This material is available free of charge via the Internet at http://pubs.acs.org.

\section{References}

(1) Diels, O.; Alder, K. Synthesen in Der Hydroaromatischen Reihe. Justus Liebigs Ann. Chem. 1928, 460, 98-122.

(2) March, J. Reactions Mechanisms and Structure. Advanced Organic Chemistry, 4th ed.; Wiley: New York, 1992, 842-852 and references therein.

(3) Sankararaman, S. In Pericyclic Reactions-A Textbook: Reactions, Applications and Theory. Wiley: Weinheim, 2005.

(4) Kobayashi, S. Jorgensen, K. A. Eds. Cycloaddition Reactions in Organics Synthesis. Wiley VCH: Weinheim, 2001.

(5) Fleming, I. In Frontier Orbitals and Organic Chemical Reaction. Wiley: New York, 1976.

(6) Desimoni, G.; Tacconi, G.; Barco, A.; Pollini, G. P. Natural Product Synthesis through Pericyclic Reactions. ACS Monographe 180 ACS, Washington DC, Chap 5 1983, 119.

(7) Cigane, K. E. The Intramolecular Diels-Alder Reaction. Organic reactions 1984, 32, 1-374.

(8) Craig, D. Stereochemical Aspects of the Intramolecular Diels-Alder Reaction. Chem. Soc. Rev. 1987, 16, $187-238$.

(9) Himbert, G.; Henn, L. Intramolecular Diels-Alder Reaction of Allenecarboxanilides. Angew. Chem., Int. Ed. 1982, 21, 620-620.

(10) Diehl, K.; Himbert, G.; Henn, L. Cycloadditionen, 7. Intramolekulare Diels-Alder Reaktionen bei Allencarboxaniliden; Variation der Substituenten in p-Position des Anilinkerns. Chem. Ber. 1986, 24302443.

(11) Himbert, G.; Fink, D.; Diehl, K. Cycloadditionen, 12. Einfluß von Alkylgruppen am Aromaten auf die Intramolekulare Diels-Alder Reaktion von allencarbonsäure-arylestern und Allencarboxaniliden. Chem. Ber. 1988, 121, 431-441.

(12) Henn, L.; Himbert, G.; Diehl, K.; Kaftory, M. Cycloadditionen, 6. Intramolekulare Diels - Alder Reaktion bei Allencarboxaniliden; Variation des zur Carboxamidgruppe Geminal Stehenden Restes; Chem. Ber. 1986, 119, 1953-1963.

(13) Diehl, K.; Himbert, G. Cycloadditionen, 11. Intramolekulare Diels - Alder-Reaktionen bei Allencarboxaniliden; Synthese und Thermolyse von Vinylidenmalondiamiden. Chem. Ber. 1986, 119, 3812-3825. 
(14) Himbert, G.; Fink, D. Cycloadditionen. 26. Einfluß von Substituenten in der allenischen $\omega$ - Position auf das Thermische Verhalten von Allencarbonsäurearylester; J. Prakt. Chem. 1997, 339, 233-242.

(15) Himbert, G.; Fink, D. Cycloadditionen. 23 [1]. Zur Thermischen Reaktivität von S-(1-Naphthyl)-und S(9-Anthryl)-2-methyl-buta-2,3-Dienthiosäureestern; J. Prakt. Chem. 1994, 336, 654-657

(16) Schmidt, Y.; Lam, J. K.; Pham, H. V.; Houk, K. N.; Vanderwal, C. D. Studies on the Himbert Intramolecular Arene/Allene Diels-Alder Cycloaddition. Mechanistic Studies and Expansion of Scope to All-Carbon Tethers. J. Am. Chem. Soc. 2013, 135, 7339-7348.

(17) Lam, J. K.; Schmidt, Y.; Vanderwal, C. D. Complex Polycyclic Scaffolds by Metathesis Rearrangement of Himbert Arene/Allene Cycloadducts. Org. Lett. 2012, 14, 5566-5569.

(18) Lam, J. K.; Pham, H. V.; Houk, K. N.; Vanderwal, C. D. Computation and Experiment Reveal That the Ring-Rearrangement Metathesis of Himbert Cycloadducts can be Subject to Kinetic or Thermodynamic Control. J. Am. Chem. Soc. 2013, 135, 17585-17594.

(19) Pham, H. V.; Karns, A. S.; Vanderwal, C. D.; Houk, K. N. Computational and Experimental Investigations of the Formal Dyotropic Rearrangements of Himbert Arene/Allene Cycloadducts. J. Am. Chem. Soc. 2015, 137, 6956-6964.

(20) Exner, O.; Krygowski, T. M. The Nitro Group as Substituent. Chem. Soc. Rev. 1996, 25, 71-75.

(21) Hammett, L. P. The Effect of Structure upon the Reactions of Organic Compounds. Benzene Derivatives. J. Am. Chem. Soc. 1937, 59, 96-103.

(22) Mardirossian, N.; Head-Gordon, M. Thirty Years of Density Functional Theory in Computational Chemistry: an Overview and Extensive Assessment of 200 Density Functionals. Molecular Physics, 2017, $115,2315-2372$.

(23) Goerigk, L.; Hansen, A.; Bauer, C.; Ehrlich, S.; Najibi, A.; Grimme, S. A Look at the Density Functional Theory zoo with the Advanced GMTKN55 Database for General Main Group Thermochemistry, Kinetics and Noncovalent Interactions. Phys. Chem. Chem. Phys. 2017, 19, 3218432215.

(24) Zhao, Y.; Truhlar, D.G. The M06 Suite of Density Functionals for Main Group Thermochemistry, Thermochemical Kinetics, Noncovalent Interactions, Excited States, and Transition Elements: two New Functionals and Systematic Testing of four M06-Class Functionals and 12 other Functionals. Theor. Chem. Acc. 2008, 120, 215-241.

(25) Zhao, Y.; Truhlar, D.G. Density Functionals with Broad Applicability in Chemistry. Acc. Chem. Res. 2008, 41, 157-167.

(26) Gaussian 09, Revision C.01, Frisch, M. J. G.; Trucks, W. H.; Schlegel, B.; Scuseria, G. E.; Robb, M. A.; Cheeseman, J. R.; Scalmani, G.; Barone, V.; Mennucci, B.; Petersson, G. A. et al. Gaussian, Inc., Wallingford CT, 2010.

(27) Kendall, R. A.; Dunning, T. H. Jr.; Harrison, RJ. Electron Affinities of the First-row Atoms Revisited. Systematic Basis Sets and Wave Functions. J. Chem. Phys. 1992, 96, 6796-6806.

(28) Woon, D. E.; Dunning, T. H. Jr. Gaussian Basis sets for use in Correlated Molecular Calculations. III. The Atoms Aluminum Through Argon. J. Chem. Phys. 1993, 98, 1358-1371.

(29) González, C.; Schlegel, H. B. Reaction Path Following in Mass-weighted Internal Coordinates. J. Phys. Chem. 1990, 94, 5523-5527.

(30) Reed, A. E.; Curtiss, L. A.; Weinhold, F. Intermolecular Interactions from a Natural Bond Orbital, Donoracceptor Viewpoint. Chem. Rev. 1988, 88, 899-926.

(31) Foster, J. P.; Weinhold, F. Natural Hybrid Orbitals. J. Am. Chem. Soc. 1980, 102, 7211-7218.

(32) Reed, A. E.; Weinhold, F. Natural Localized Molecular Orbitals. J. Chem. Phys. 1985, 83, 1736-1740.

(33) Reed, A. E.; Weinstock, R. B.; Weinhold, F. Natural Population Analysis. J. Chem. Phys. 1985, 83, 735746.

(34) Glendening, E. D.; Reed, A. E.; Carpenter, J. E.; Weinhold, F. NBO Version 3.1.

(35) Tognetti, V.; Morell, C.; Ayers, P. W.; Joubert, L.; Chermette, H. A Proposal for an Extended Dual Descriptor: a Possible Solution when Frontier Molecular Orbital Theory Fails. Phys. Chem. Chem. Phys. 2013, 15, 14465- 14475 . 
(36) Proft, F. D.; Forquet, V.; Ourri, B.; Chermette, H.; Geerlings, P.; Morell, C. Investigation of Electron Density Changes at the Onset of a Chemical Reaction using the State-Specific Dual Descriptor from Conceptual Density Functional Theory. Phys. Chem. Chem. Phys. 2015, 17, 9359- 9368.

(37) Choo, J.; Kim, S.; Joo, H.; Kwon, Y. Molecular Structures of (trifluoromethyl)iodine Dihalides CF3IX2 (X=F, Cl): ab initio and DFT Calculations. J. Mol. Struct. (Theochem) 2002, 587, 1-8.

(38) Dewar, M. J. S. Multibond Reactions Cannot Normally be Synchronous. J. Am. Chem. Soc. 1984, 106, 209-219.

(39) Borden, W. T.; Loncharich, R. J.; Houk, K. N. Synchronicity in Multibond Reactions. Annu. Rev. Phys. Chem. 1988, 39, 213-236.

(40) Wiberg, K. B. Application of the Pople-Santry-Segal CNDO Method to the Cyclopropylcarbinyl and Cyclobutyl Cation and to Bicyclobutane; Tetrahedron 1968, 24, 1083- 1096. 


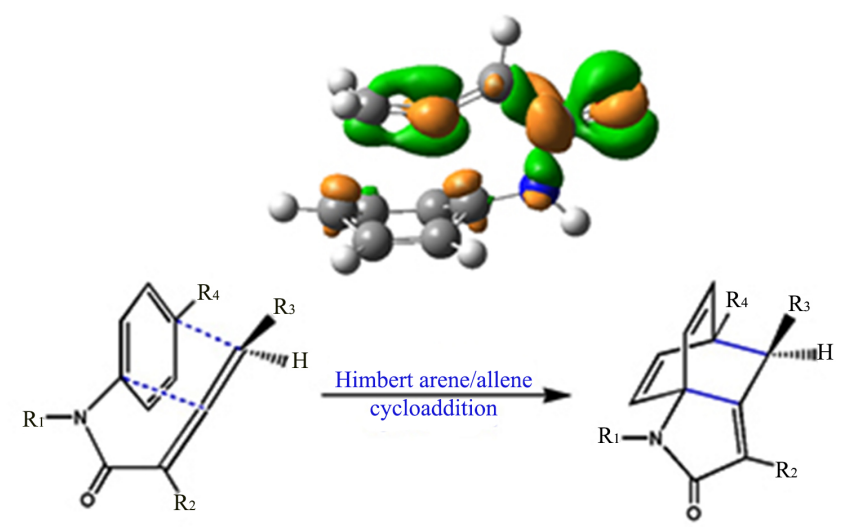

Conceptual density functional theory has been applied to study the Himbert intramolecular arene/allene Diels-Alder reaction. The effect of substitutions on the kinetics of 27 reactions has been analyzed with the aid of conceptual DFT descriptors and NBO analysis. 